\title{
Environmental Control of Amnesic Effects of Various Agents in Goldfish'
}

\author{
R. E. DAVIS AND P. D. KLINGER \\ Mental Health Research Institute, University of Michigan, Ann Arbor
}

(Received 6 November 1968)

\begin{abstract}
DAvis, R. E. AND P. D. KLINGER. Environmental control of amnesic effects of various agents in goldfish. PHYSIOL. BEHAV. 4(2) 269-271, 1969. - Fish given a single electroconvulsive shock or intracranial administration of puromycin, acetoxycycloheximide, or $\mathrm{KCl}$ immediately following shock avoidance training show amnesia on retraining days later. When the treatments are given $24 \mathrm{hr}$ after training no amnesia develops. But amnesia can be obtained $24 \mathrm{hr}$ after training with $\mathrm{KCl}$, puromycin and acetoxycycloheximide, if the fish are replaced in the intertrial environment for a brief period just prior to injection. Implications of these results to the consolidation hypothesis of memory formation are discussed. Previously unreported results on the amnesic effects of intracranial $\mathrm{KCl}$ in goldfish are also described.
\end{abstract}

$\begin{array}{lllll}\text { Amnesia } & \text { Memory consolidation } & \text { Memory formation Shock avoidance } & \text { Conditioning Goldfish } \\ \text { Puromycin } & \text { Acetoxycycloheximide } & \mathrm{KCl} \text { Electroconvulsive shock }\end{array}$

PrEvious investigations in goldfish have yielded evidence that electroconvulsive shock (ECS) and intracranial administration of puromycin, acetoxycycloheximide and actinomycin $\mathrm{D}$ interfere with the consolidation of memory of shock avoidance $[1,2,3,8,9]$. Some results obtained with puromycin have further indicated that memory formation may be delayed or suppressed by stimuli in the training environment. We found that when fish are returned to home tanks immediately following training the susceptibility of avoidance responding to interference by puromycin decreases within minutes and disappears within several hours. But when fish are kept in the intertrial environment prior to puromycin injection, up to several hours following training, no decrease in puromycin susceptibility is detected $[1,7]$. While these results suggest that consolidation, or some stage of memory formation, is controlled by stimuli in the training environment, they could indicate that puromycin produces amnesia by interacting with external environmental stimuliand not by disrupting memory formation. The present investigation was to test the possibility that amnesia can be produced after memory has ostensibly been consolidated by exposing fish to the intertrial environment (ITE) for a short period immediately prior to administration of various amnesic agents.

The ITE effect was tested with puromycin, acetoxycycloheximide, ECS and intracranial administration of $\mathrm{KCl}$. The use of $\mathrm{KCl}$ as an amnesic agent in goldfish was suggested by reports that applications of $\mathrm{KCl}$ which induce spreading depression in rats also block memory consolidation $[4,5]$. The amnesic effects of intracranial $\mathrm{KCl}$ administered at various times after the training session are described before the ITE experiments.
METHOD

Shock-avoidance responding was conditioned in the procedure previously designated task III $[2,6]$. Fish were transferred from large stock tanks to the individual home tanks the day before an experiment. On Day 1 of an experiment, fish were moved in home tanks to the experimental room, placed in individual shuttleboxes [3] for $5 \mathrm{~min}$ and then given 20 trials in $20 \mathrm{~min}$. At the start of a trial, the stimulus lamp outside the compartment containing the fish, was turned on. After $15 \mathrm{sec}$, a repetitive electrical shock was presented in the light compartment for an additional $20 \mathrm{sec}$. A trial automatically terminated after $35 \mathrm{sec}$ or when the fish crossed over the barrier to the dark compartment. Fish could avoid the shock by crossing the barrier during the first $15 \mathrm{sec}$ of a trial or escape from it by crossing during the last $20 \mathrm{sec}$. Avoidances and escapes were registered by a 20 pen Esterline-Angus operations recorder. Movement of fish over the barrier was registered by a photodetector which was continuously illuminated by a narrow beam of light flanking the barrier in each compartment. Fish were replaced in home tanks immediately following the last trial then returned to the storage room. To test retention of avoidance responding, fish were returned to the shuttleboxes and, after $5 \mathrm{~min}$, given 10 additionai trials in $10 \mathrm{~min}$. During the first $5 \mathrm{~min}$ of the training and of the retraining sessions, and in the 25-sec intertrial interval, the shuttlebox was dark except for the thin, photo-conductor light-beam in each compartment. This environment is referred to as the ITE.

Retention was evaluated by contrasting the number of avoidances a fish achieved (A) in the 10 retraining trials to the number predicted (P) on the basis of data for independent

\footnotetext{
${ }^{1}$ Supported by NIMH and NSF grants, and NIMH research development award K2-MH-22,183 (R.E.D.). Presented, in part, at the 1968 Meeting of the American Institute of Biological Sciences, Columbus, Ohio, September 1968 [Davis, R. E., Am. Zool. 8: 697 (1968)].
} 
controls. We recorded 6 scores for individual fish; these were the number of avoidances and of failures to escape in trials $1-10,11-20$ and $21-30$. Fish who made 6 or more avoidances or more than 4 failures to escape in trials 1-10 were rejected, as were fish who failed to escape more than 4 times in trials 21-30. The remaining fish, about 90 per cent of the total, fell into two classes: Class $I$, no avoidance in trials 1-20; Class II, one or more avoidances in trials 1-20. Weekly Class I and II prediction equations were obtained from about 40 , independent controls of each class trained that week and 2 weeks before and 2 weeks after. For Class I, the two variables used to obtain $P$ were the failures to escape in trials $1-10$ and 11-20. For Class II the two variables were the total number of avoidances in trials $1-20$ and the failures to escape in trials 1-10.

Our method of injecting dissolved substances into the cranial cavity of goldfish is described elsewhere [3]. Fish received $130 \mu \mathrm{g}$ of puromycin, $0.2 \mu \mathrm{g}$ of acetoxycycloheximide, or $600 \mu \mathrm{g}$ of $\mathrm{KCl}$ dissolved in $10 \mu \mathrm{l}$ of $0.15 \mathrm{M} \mathrm{NaCl}$.

ECS was produced by a $100 \mathrm{msec}, 8 \mathrm{~mA}$, pulse of $115 \mathrm{~V}$ a.c. delivered by electrodes which were pressed on the roof of the cranium immediately posterior to the orbits. We held a fish in one hand and delivered the shock with the other.

\section{RESULTS}

\section{Part 1. Intracranial $\mathrm{KCl}$}

The $\mathrm{KCl}$ injection produced immediate seizures. Convulsive swimming movements diminished in intensity over a period of 1-2 hr after which the fish showed normal movements and postures. The injection killed up to 20 per cent of the fish and nearly every death occurred during the seizure period.

To investigate the amnesic effects of $\mathrm{KCl}$, goldfish returned to home tanks immediately following training were injected at various times up to $24 \mathrm{hr}$ later and then retrained on Day 4. The results in Table 1 reveal that the groups injected within $18 \mathrm{hr}$ after training showed retention deficits but that the group injected at $24 \mathrm{hr}$ showed normal retention. For the group injected immediately posttrial the mean achieved score (A) was statistically equivalent to their mean score in the first 10 trials on Day $1(0.39)$ indicating complete amnesia for the avoidance response.

TABLE 1.

EFFECT ON RETENTION OF AVOIDANCE RESPONDING OF ADMINISTERING INTRACRANIAL $\mathrm{KCl}$ at VARIOUS TIMES Following TraINING

\begin{tabular}{|c|c|c|c|c|}
\hline \multirow{2}{*}{$\begin{array}{l}\text { Posttrial } \\
\text { injection } \\
\text { time }\end{array}$} & \multirow[b]{2}{*}{$\mathbf{N}$} & \multicolumn{3}{|c|}{ Day 4 Score } \\
\hline & & $\begin{array}{l}\text { Achieved } \\
\text { (A) }\end{array}$ & $\begin{array}{l}\text { Predicted } \\
\text { (P) }\end{array}$ & $\begin{array}{l}\text { Retention } \\
\quad(\mathrm{A}-\mathrm{P})\end{array}$ \\
\hline immediate & 28 & 0.96 & 4.18 & $-3.22^{*}$ \\
\hline $4 \mathrm{hr}$ & 26 & 2.04 & 3.96 & $-1.92^{*}$ \\
\hline $8 \mathrm{hr}$ & 25 & 2.04 & 3.48 & $-1.44^{*}$ \\
\hline $12 \mathrm{hr}$ & 22 & 2.82 & 4.88 & $-2.06^{*}$ \\
\hline $18 \mathrm{hr}$ & 41 & 3.29 & 4.98 & $-1.68^{*}$ \\
\hline $24 \mathrm{hr}$ & 35 & 4.14 & 4.44 & -0.30 \\
\hline
\end{tabular}

${ }^{*}$ A vis. P. $p<0.01$
The next experiment was to estimate the rate at which amnesia develops when $\mathrm{KCl}$ is given immediately after training, as a further basis for comparison of the amnesic effects of $\mathrm{KCl}$ with those of ECS and the antibiotics. Groups of fish were administered $\mathrm{KCl}$ immediately following training, returned to home tanks and then retrained 6,12 or $24 \mathrm{hr}$ later. The group retrained at $6 \mathrm{hr}$ had a deficit of -1.16 which was significantly smaller $(p<0.05)$ than the deficits shown by fish retrained at $12 \mathrm{hr}(-3.19)$ or $24 \mathrm{hr}(-3.45)$. The deficits at 12 and $24 \mathrm{hr}$ are not significantly different from the deficit for fish retrained at $72 \mathrm{hr}$ (Day 4; Table 1). These results indicate that $\mathrm{KCl}$-produced amnesia develops in 6-12 hr.

\section{Part 2. The ITE Effect}

In these experiments fish were returned to home tanks immediately following training, kept there for $24 \mathrm{hr}$ and then replaced in the shuttleboxes in the intertrial environment (ITE). The foregoing results with $\mathrm{KCl}$, and results previously obtained with ECS and the antibiotics $[2,9]$, indicated that after $24 \mathrm{hr}$ in the home tanks, retention of avoidance responding is resistant to interference by these agents. We sought to test whether interpolation of the ITE period just before administering the various agents $24 \mathrm{hr}$ posttrial results in amnesia. For the ITE period on Day 2, the fish were handled as though they were to be trained, but the light and shock stimuli of avoidance trials were withheld. Immediately following the ITE period, different fish were administered $\mathrm{ECS}$, and intracranial $\mathrm{KCl}$, puromycin, and acetoxycycloheximide and then returned to home tanks. Some fish were

TABLE 2.

THE ITE EFFECT

\begin{tabular}{lrrrrc}
\hline $\begin{array}{l}\text { Treatment } \\
\text { on Day 2 }\end{array}$ & $\begin{array}{c}\text { Retraining } \\
\text { Day }\end{array}$ & & $\begin{array}{c}\text { Achieved } \\
\text { (A) }\end{array}$ & $\begin{array}{c}\text { Predicted } \\
\text { (P) }\end{array}$ & $\begin{array}{c}\text { Retention } \\
\text { (A-P) }\end{array}$ \\
\hline ITE & 4 & 24 & 5.33 & 5.31 & +0.02 \\
& 8 & 22 & 4.54 & 4.82 & -0.27 \\
ITE-KCl & 4 & 24 & 2.29 & 6.08 & $-3.76^{*}$ \\
ITE-puromycin 4 & 29 & 5.89 & 5.05 & -0.83 \\
& 8 & 28 & 2.54 & 4.20 & $-1.66 \dagger$ \\
ITE-acetoxy- & 4 & 30 & 5.87 & 5.33 & -0.54 \\
cycloheximide & 8 & 25 & 2.76 & 4.46 & $-1.70 \dagger$ \\
ITE-ECS & 4 & 27 & 4.56 & 5.32 & -0.76 \\
& 8 & 24 & 4.88 & 4.81 & +0.06 \\
Puromycin & 8 & 27 & 4.04 & 4.08 & -0.04 \\
Acetoxy & 3 & 25 & 4.16 & 4.53 & -0.38 \\
cycloheximide & & & & & \\
None & 8 & 23 & 4.00 & 3.95 & -0.05 \\
& & & & & \\
\hline
\end{tabular}

$$
\text { *A vs. } \mathrm{P}, p<0.01
$$

+ A vs. P, $p<0.05$

retrained 2 days after the ITE period (Day 4). Fish that had received ECS, puromycin or acetoxycycloheximide showed normal retention but those given $\mathrm{KCl}$ showed virtually no retention; it was as though the $\mathrm{KCl}$ had been given immediately following the training session on Day 1 (Table 2). Other fish given ECS and the antibiotics were retrained 6 days after the ITE period (Day 8) to test the possibility that these agents produce amnesia which takes more than 2 days to 
develop. As shown in Table 2, fish given ECS on Day 2 showed normal retention 6 days later but fish given puromycin or acetoxycycloheximide showed moderate retention deficits. Other groups which received only puromycin or acetoxycycloheximide or the ITE period on Day 2 showed normal retention on Day 8 (Table 2).

The rate of development of the amnesia produced by the ITE- $\mathrm{KCl}$ treatment on Day 2 was estimated by retraining fish $24 \mathrm{hr}$ after injection (Day 3 ). The fish showed a retention deficit of -1.10 which is significantly smaller $(p<0.01)$ than the deficit for fish retrained $48 \mathrm{hr}$ after injection $(-3.76$; see Table 2) indicating that the amnesia developed over a period of $24-48 \mathrm{hr}$. KCl thus produced amnesia 2-3 times more slowly than when it was given immediately posttrial (6-12 hr; see Part 1).

\section{DISCUSSION}

The susceptibility of newly learned responses to interference by various treatments which disturb brain function has been the most persuasive evidence for the memory consolidation hypothesis. The ITE effect reveals that amnesia produced by posttrial administration of some agents cannot be attributed solely to a block of memory formation. Intracranial $\mathrm{KCl}$, puromycin, and acetoxycycloheximide may disrupt consolidation when administered shortly posttrial (or possibly pretrial $[1,8]$ ) but the amnesia which develops when they are paired with the ITE period on Day 2 must have a different origin. The fact that amnesia developed more slowly after ITE- $\mathrm{KCl}$ on Day 2 than after training-ITE on
Day 1, suggests that the ITE effect may decrease over time following training. When puromycin is given immediately posttrial, amnesia develops in 2-3 days [8]; similar results, to be reported elsewhere, have been obtained for acetoxycycloheximide. In contrast, the data in Table 2 suggest that the ITE-puromycin and ITE-acetoxycycloheximide interactions produced amnesia which takes more than 6 days to fully develop.

While the consolidation interpretation is inadequate to account for behavioral effects of some amnesic agents in goldfish, they lend support to no single alternative model. Our results relate to those of recent experiments with ECS in rats. Schneider and Sherman [12] and Misanin, Miller and Lewis [11] report that ECS-produced amnesia can be obtained after memory is ostensibly fixed to ECS, if a stimulus from the training situation is presented just before the ECS. Misanin, ct al. suggest that ECS interferes with active memory and that memory activation is mediated by the prevalence of stimuli related to the memory. This scheme does not readily accomodate our data since they indicate that the ITE does not interact with ECS (Table 2). Possibly ITE-ECS produced amnesia develops after more than 6 days. Excitement, or arousal engendered by exposure to stimuli in the training environment may interact with effects of amnesic agents [7, 8, 12]. The possibility that amnesic agents have stimulus effects which interfere with avoidance responding by reinforcing a competing response [10], such as freezing, cannot be rejected. In light of previous inferences about the physiology of memory formation, environmental control of behavioral effects of amnesic agents clearly needs extensive investigation.

\section{REFERENCES}

1. Agranoff, B. W., R. E. Davis and J. J. Brink. Memory fixation in the goldfish. Proc. Natl. Acad. Sci., U.S. S4 (3): 788, 1965.

2. Agranoff, B. W., R. E. Davis, L. Casola and R. Lim. Actinomycin $\mathrm{D}$ blocks formation of memory of shock-avoidance in goldfish. Science 158: 1600-1601, 1967.

3. Agranoff, B. W. and P. D. Klinger. Puromycin effect on memory fixation in the goldfish. Science 146: 952-953, 1964.

4. Avis, H. H. and P. L. Carlton. Retrograde amnesia produced by hippocampal spreading depression. Science 161: 73-75, 1968.

5. Bures, J. and O. Buresova. Cortical spreading depression as a memory disturbing factor. J. comp. physiol. Psychol. 56: 268-272, 1963.

6. Casola, L., R. Lim, R. E. Davis and B. W. Agranoff. Behavioral and biochemical effects of intracranial injection of cytosine arabinoside in goldfish. Proc. Nat. Acad. Sci., U.S. 60: 1389$1395,1968$.
7. Davis, R. E. Environmental control of memory fixation in goldfish. J. comp, physiol. Psychol. 65: 72-78, 1968.

8. Davis, R. E. and B. W. Agranoff. Stages of memory formation in goldfish: Evidence for an environmental trigger. Proc. Nat. Acad. Sci., U.S. 55: 555-559, 1966.

9. Davis, R. E., P. J. Bright and B. W. Agranoff. Effect of ECS and puromycin on memory in fish. J. comp. physiol. Psychol. 60: 162-166, 1965.

10. Lewis, D. J. and B. A. Maher. Neural consolidation and electroconvulsive shock. Psychol Rev. 72: 225-239, 1965.

11. Misanin, J. R., R. R. Miller and D. J. Lewis. Retrograde amnesia produced by electroconvulsive shock after a reactivation of consolidated memory trace. Science 160: 554-555, 1968.

12. Schneider, A. M. and W. Sherman. Amnesia: A function of the temporal relation of footshock to electroconvulsive shock. Science 159: 219-221, 1968. 